\title{
SUBJETIVIDADES
}

Relato de Pesquisa

e-ISSN: 2359-0777

\section{INTERSETORIALIDADE EM SAÚDE MENTAL: TENSÕES E DESAFIOS EM CIDADES DO SUDESTE E NORDESTE BRASILEIRO}

Intersectoriality in Mental Health: Tensions and Challenges in Cities of Southeastern and Northeastern Brazil

\section{Intersectorialidad en Salud Mental: Tensiones y Retos en Ciudads del Sudeste y del Nordeste Brasileño}

\section{L'Intersectionnalité dans la Santé Mentale: Tensions et Défis dans Villes du Sud-Est et du Nord-Est brésilien}

DOI: $10.5020 / 23590777 . r s . v 17 i 3.6075$

Roberta Carvalho Romagnoli (OrcID)

Professora Adjunto III do Programa de Pós-Graduação em Psicologia da PUC Minas.

Ana Karenina de Melo Arraes Amorim (OrcID)

Professora do Departamento de Psicologia e do Programa de Pós-graduação em Psicologia da UFRN.

Ana Kalliny de Sousa Severo (OrcID)

Professora do Curso de Psicologia da Universidade Federal do Piaú.

Maria Teresa Nobre (OrcID)

Professora do Departamento de Psicologia e do Programa de Pós-Graduação em Psicologia da UFRN.

\section{Resumo}

Este artigo aborda a problemática da intersetorialidade no campo da saúde mental no Brasil, analisando suas práticas na cidade de Belo Horizonte, em Minas Gerais, e Natal, no Rio Grande do Norte. A partir das ideias de Deleuze e Guattari e tomando como campo de análise as pesquisas realizadas pelas autoras nas duas cidades, pensamos a estratégia da intersetorialidade como um rizoma, como uma rede que se autoengendra por agenciamentos com os mais variados elementos da realidade, permitindo ao mesmo tempo rastrear as reproduções e os deslocamentos inventivos que se libertam das estruturas cristalizadas presentes da ação intersetorial. Concluímos que, embora em regiões distintas, com territórios singulares, a intersetorialidade ainda encontra os seguintes desafios: falta de articulação entre sistemas e serviços, precariedade de comunicação entre as equipes, sensação de sobrecarga de trabalho dos profissionais, risco de psicologização dos casos e falta de avaliação das ações em conjunto após os encaminhamentos.

Palavras-chave: politicas públicas; intersetorialidade; saúde mental; rizoma

Abstract

This article discusses intersectioriality in the field of brazilian mental health, analyzing its practices in the city of Belo Horizonte, Minas Gerais and in the city of Natal, Rio Grande do Norte. Based on the ideas of Deleuze and Guattari and taking the analysis made in the researches made by the authors in the two cities, we approach the strategy of intersectoriality as a rhizome, like a network that is self-engendered by assemblages with the most varied elements of reality, allowing at the same time to trace the reproductions and the inventive displacements that detaches of crystallized structures of intersectorial action. We conclude that, although in different regions, with unique territories, the intersectoriality still faces the following challenges: lack of articulation between systems and services, precarious 
communication between teams, feeling of work overload, risk of psychologizing of cases and lack of evaluations together after the referrals.

Keywords: public policies; intersectioriality; mental health; rhizome.

\section{Resumem}

Este artículo aborda el problema de la interseccionalidad en el campo de la salud mental en Brasil, examinando sus prácticas en la ciudad de Belo Horizonte, Minas Gerais y en Natal, Rio Grande do Norte. A partir de las ideas de Deleuze y Guattari y tomando como análisis de la investigación de campo realizada por los autores en las dos ciudades, pensamos que la estrategia intersectorial como un rizoma, con una red que autoengendra por ensamblajes con varios elementos de la realidad, permitiendo al mismo tiempo la reproducción y los movimientos de la invención que liberan las estructuras cristalizadas presente en la acción intersectorial. Llegamos a la conclusión de que, aunque en diferentes regiones y las zonas unicas, la intersectorialidad encuentra los siguientes desafios: falta de coordinación entre los sistemas y servicios, la precariedad de la comunicación entre los equipos, sensación de sobrecarga de trabajo, la psicologización riesgo de casos y la falta de evaluaciones las acciones juntos después de referencias.

Palabras clave: politicas públicas; intersectorialidad; salud mental; rizoma.

\section{Resumé}

Ce texte cherche à discuter l'intersectionnalité dans le domaine de la santé mentale au Brésil, en analysant leurs pratiques dans la ville de Belo Horizonte, Minas Gerais et Natal, Rio Grande do Norte. Pour ce faire, les nous avons pris les idées Deleuze et Guattari' et le champ de anlayses des recherches menées par les auteurs dans les deux villes. Dasns ce contexte, nous pensons la stratégie intersectorielle comme un rhizome, comme un réseau qui si produit par des assemblages avec divers éléments de la réalité, en permettant lalecture de les reproductions et des mouvements inventifs qui libèrent des structures cristallisées présente d'action intersectorielle. Nous concluons que, bien que dans différentes régions, avec des territoires individuels, l'intersectorialité trouve encore les défis suivants: manque de coordination entre les systèmes et services, la précarité de la communication entre les équipes, le sens de la surcharge de travail professionnel, la psychologisation de scas et le manque des évaluations des actions ensemble après les références.

Mots-clés: politique publique; intersectionnalité; santé mentale; rhizome.

A Constituição Brasileira de 1988 compõe um sistema de seguridade social que reconhece o direito às estruturas democráticas e à proteção social para toda a população, inclusive para os não segurados. Esse documento, resultado de intensa mobilização social, sustenta um padrão de proteção social mais igualitário e universalista, modificando a concepção vigente das políticas públicas brasileiras até então. Baseadas no texto da Constituição, as políticas públicas passam a se responsabilizar pela proposição e fortalecimento de ações (planos, programas e projetos) que possibilitem melhorias nas condições de vida das populações, realizando ações que indicam a necessidade de articulação entre essas políticas e que são definidas como intersetorialidade, enquanto diretriz presente no texto constitucional, desde a sua promulgação. Entretanto, a institucionalização dessas políticas, notadamente através do Sistema Único de Saúde (SUS) e Sistema Único da Assistência Social (SUAS), observa muitas fragilidades na implementação da intersetorialidade. Isso porque a definição setorial das políticas e a gestão segmentada e setorializada demonstram a ineficiência ou ausência de ações integradas e já não respondem adequadamente aos desafios atuais, produzindo efeitos diretos sobre a atenção aos usuários.

No Brasil, a experiência italiana, denominada Psiquiatria Democrática, inspira o movimento da Reforma Psiquiátrica, na busca da desinstitucionalização da loucura. Com esse processo, a partir de 2001 (ano da promulgação da Lei 10.216/2001, conhecida como Lei da Reforma Psiquiátrica), inicia-se outro modelo de atenção em Saúde Mental, que introduz diferentes instrumentos e dispositivos na tentativa de promover a desconstrução do modelo manicomial asilar. Nesse contexto, os serviços substitutivos de saúde mental representam uma importante mudança de paradigma que tende cada vez mais a se concentrar nos territórios e não nos hospitais. As equipes multidisciplinares e o apoio das comunidades se mostraram fundamentais para melhor adesão ao tratamento, além de propiciar uma nova maneira de perceber o adoecimento mental (Lancetti \& Amarante, 2008).

O paradigma da desinstitucionalização supõe em suas bases epistemológicas e conceituais a amplitude cultural do processo de desconstrução dos saberes e práticas que reduzem a loucura à doença mental e que, consequentemente, reforçam a instituição hospitalar e o setor saúde como únicas referências para a atenção. Assim, nesse paradigma, a produção de saúde mental não se daria mais apenas a partir de parâmetros biomédicos, mas pela "produção da vida possível e com 
sentido para os sujeitos em suas singularidades nos diferentes espaços de sociabilidade e solidariedade em que circulam" (Arraes-Amorim \& Dimenstein, 2009, p. 197), ou seja, a produção de saúde mental passa necessariamente pela construção da intersetorialidade e do trabalho em uma rede articulada de saberes e práticas, de tal modo que esse passa a ser o principal desafio para a desinstitucionalização (Dimenstein \& Liberato, 2009).

A Estratégia Saúde da Família é a estratégia primordial de atenção em saúde na Atenção Básica no Brasil. Na Rede de Atenção Psicossocial, a Atenção Básica busca integrar serviços para assistir integralmente seus usuários, a partir de uma equipe multidisciplinar, de maneira a trazer impactos na situação de saúde, e atuar nos determinantes de saúde da população, incluindo as condições de vida, em seu sentido mais amplo. Além das equipes de saúde da família (ESFs), são estratégicas as equipes do Núcleo de Atenção à Saúde da Família (NASF) no apoio matricial e cuidado compartilhado, tendo por função dar suporte às ESFs no manejo de situações relacionadas ao transtorno mental e aos Consultórios na Rua (CnaR), que atuam de forma itinerante ofertando cuidados à saúde para a população em situação de rua a partir de suas diferentes necessidades. Já o Centro de Atenção Psicossocial (CAPS) deve ser agenciador da mudança na rede, construindo um trabalho territorial ao contribuir para a potencialização dos recursos das redes intra-setorial e intersetorial, assegurando a ampliação do cuidado e o acesso ao tratamento (Delgado, 2013).

A discussão acerca da intersetorialidade na saúde mental tem se fortalecido, principalmente a partir do ano de 2010, quando ocorreu a IV Conferência Nacional de Saúde Mental-Intersetorial e, pela primeira vez, os parceiros intersetoriais (da Assistência Social, Cultura, Segurança Pública, Justiça, Economia, entre outros) foram convocados oficialmente para o debate.

Analisando a intersetorialidade, Monnerat e Souza (2011) apontam para a necessidade de um enfrentamento intersetorial através da conformação de uma rede de proteção social, com a construção de interfaces entre setores e instituições governamentais (e não governamentais), sobretudo em uma sociedade como a do Brasil, com grandes limites estruturais e desigualdades sociais. Essa rede tem como propósito enfrentar os complexos problemas sociais, que ultrapassam a alçada de um só setor de governo ou área de política pública, tornando quase uma imposição a integração entre as políticas.

Nesse contexto, podemos definir intersetorialidade como "a articulação de saberes e experiências com vistas ao planejamento, para a realização e a avaliação de políticas, programas e projetos, com o objetivo de alcançar resultados sinérgicos em situações complexas" (Inojosa, 2001, p. 105). Para ser uma prática efetiva, essa articulação pressupõe muito mais que agregação de setores pretendendo a integralidade como estratégia de intervenção para a superação do problema em pauta. A intersetorialidade convoca um conjunto de inovações no âmbito da gestão pública, exigindo novas respostas organizativas, a superação das estruturas hierarquizadas e verticais, e a criação de novos arranjos institucionais, com estruturas horizontalizadas de trabalho, como assinala Bronzo (2010). A autora ressalta ainda que a ação setorial envolve alterações tanto nas dinâmicas e nos processos institucionais quanto no desenho e nos conteúdos das políticas setoriais, não correspondendo somente à junção dos setores das diferentes políticas públicas. Assim, além dessas mudanças institucionais, a intersetorialidade também deve atuar no cotidiano dos serviços como um

dispositivo para propiciar encontros, escuta e alteridade, além de ajudar a explicitar interesses divergentes, tensões e buscar (ou reafirmar a impossibilidade) convergências possíveis. E, que também possa evitar duplicidade de ações e buscar integrações orçamentárias para projetos prioritários, articular recursos, ideias e talentos (Akerman et al., 2014, p. 4293).

Aliás, esse não é o único desafio da intersetorialidade. Ao examinar a integração das políticas sociais no Brasil, Monnerat e Souza (2011) assinalam que um forte empecilho para sua efetivação é a própria diferença entre os setores. Para as autoras, enquanto a saúde discute com sua trajetória histórica já consolidada, as múltiplas e complexas determinações do processo saúdedoença a partir da promoção da saúde investindo na ação intersetorial, a assistência social ainda possui frágil institucionalização, com dificuldades na implantação de seus equipamentos e baixo percentual de corpo técnico concursado devido ao seu legado histórico clientelista. Mesmo com essas diferenças nos dois setores, a necessidade da intersetorialidade é reconhecida, uma vez que muitas das ações necessárias para a promoção da saúde social envolvem instâncias que se encontram fora desses domínios. O mesmo ocorre na Assistência Social, que, ao buscar promover a inclusão social ou melhorar a qualidade de vida resolvendo os problemas concretos que atingem a população de um dado território, lida com demandas multifacetadas que exigem respostas para além da repartição setorial com ações coordenadas entre diferentes setores do Estado.

Ckagnazaroff e Mota (2003) também afirmam que a complexidade do processo de trabalho na intersetorialidade gera divergências entre os profissionais que vão desde os conflitos entre os diferentes tipos de conhecimentos até a delimitação das prioridades de cada região. Ao estudar a intersetorialidade no campo da educação, Góes e Machado (2013) destacam que os próprios serviços são objeto de disputas e conflitos, apresentando relações de poder que atrapalham essa associação. Sposati (2013), ao estudar a proteção social no Brasil, revela que a descontinuidade, a não integralidade, o fracionamento e a não igualdade de acesso e de reconhecimento ainda persistem nesse campo, contribuindo para que a competição e o individualismo o invadam. 
Com certeza, as ações intersetoriais burlam a endogenia dos setores envolvidos e não somente convocam a iniciativa deles, mas exigem receptividade entre as politicas setoriais, propriedades nem sempre fáceis de serem alcançadas. Conforme Andrade (2006), a ação intersetorial se sustenta na construção de objetos de intervenção comuns entre diferentes setores, para um planejamento integrado no enfrentamento dos problemas identificados. No entanto, como vimos nas pesquisas que realizamos e que serão discutidas a seguir, o que se observa na prática são muitos conflitos e disputas políticas entre as diferentes áreas e atores envolvidos no processo.

Esse quadro pode ser efeito de vários problemas: por um lado, da fragmentação entre diferentes disciplinas, saberes e práticas, que se reflete diretamente sobre a assistência; e, por outro, da cultura clientelista, dos modelos de gestão verticalizados e, em alguns contextos, da interferência político-partidária no âmbito da gestão e da atenção, que reduz políticas públicas a programas de governo. Portadora de todos esses problemas, a intersetorialidade convoca a transversalidade de ações no campo social em sua articulação com vários setores, como destacam Monnerat e Souza (2011).

\section{Rede-rizoma: A intersetorialidade em sua Transversalidade}

Pensar em uma rede que atue por transversalidade é apostar na potência das conexões que a intersetorialidade pode promover para que o cuidado em saúde mental se faça. Assim, é importante pensar a rede para além de um conjunto de serviços, programas ou prescrições, que funcionem de modo eficiente (Barros \& Passos, 2004). É necessário romper ainda a segmentação e entender rede como um projeto tecido entre muitos "nós", que compõem um coletivo articulado capaz de produzir fluxos que potencializem o cuidado, a atenção e a vida.

As discussões que apresentamos a seguir são produzidas a partir de experiências de pesquisa-intervenção realizadas em duas cidades brasileiras: Belo Horizonte e Natal. Nesse sentido, esse artigo refere-se a relatos de experiências de nossos estudos com o objetivo de discutir a intersetorialidade, promulgada pelas políticas públicas em nosso país, em seu cotidiano. Atentas às diferenças das regiões do Brasil, a partir do conceito de intersetorialidade, propomos-nos a analisar aqui, à luz da perspectiva esquizoanalítica, os resultados parciais desses trabalhos.

Ao desvelar o funcionamento de grupos a partir da sua prática como militante e interventor institucional, Guattari (1987) diferencia o grupo assujeitado, que persegue a hierarquização, adaptando-se a outros grupos e buscando a reprodução, do grupo sujeito, que tem vocação para se conduzir mediante processos autônomos e autogestivos, examinando os três movimentos presentes nesses dois tipos de grupo: a verticalidade e a horizontalidade, que sustentam os mecanismos de reprodução dos grupos assujeitados, e a transversalidade, presente nos grupos sujeitos.

Os movimentos da verticalidade são provocados pela introjeção das normas e das demandas instituídas nos grupos assujeitados, e os movimentos de horizontalidade são resultado da associação de setores e conhecimentos distintos sem que se estabeleça uma relação entre eles, pois não pressupõe uma partilha, uma troca. A transversalidade, por sua vez, consiste em movimentos produtivos de novas realidades, sustentando criações, processos inéditos. Desse modo, a transversalidade "é uma dimensão que pretende superar os dois impasses, o da pura verticalidade e o da pura horizontalidade; ela tende a se realizar quando uma comunicação máxima se efetua entre os diferentes níveis e, sobretudo nos diferentes sentidos" (Guattari, 1987, p. 96). Entendemos que apostar na transversalidade é não buscar reproduzir hierarquizações com o intuito de que potentes conexões se estabeleçam e a intersetorialidade se exerça, embora ela se faça na coexistência desses três movimentos.

No contexto das políticas intersetoriais, pretendemos abordar a transversalidade, essa coexistência através do conceito de rizoma, entendido pela esquizoanálise como uma rede. Segundo Jacques (2014), esse corpo de conhecimento corresponde a um princípio de apreensão do real, um método de organização do saber, que funciona com um vetor da heterogênese à medida que produz assiduamente a continuidade intensiva entre múltiplos elementos diferentes, que pertencem a domínios distintos. De acordo com Deleuze e Guattari (1980), essa rede se autoengendra por agenciamentos com os mais variados elementos da realidade, aos quais se conecta e reconecta a todo instante, não se reportando a uma unidade. Essa dinâmica de autoprodução é incessante, remetendo à forças/fluxos que não têm forma nem limites predeterminados. Tal concepção permite deslocamentos inventivos que se libertam das estruturas cristalizadas calcadas em normas e padrões reprodutivos e que impedem a criação, ou a sustentação, como nesse caso, da ação intersetorial.

O rizoma é composto por linhas que, segundo Deleuze e Parnet (1995), se dividem em linhas duras (ou molares), linhas flexíveis (ou moleculares) e linhas de fuga. As linhas duras detêm a divisão binária de setor, profissão, classe social, entre outros, e organizam nossa vida dentro de um tempo historiado e visível. No caso, delimitam a atuação de cada política setorial, de cada profissional em sua formação. Essas linhas atuam por classificação e sistematização dos fluxos da realidade, efetuando grandes cortes segmentários e assegurando a homogeneização do rizoma, que é em si heterogêneo. Ao dar determinada ordem à realidade, essas linhas compõem o plano de organização, também chamado de estrato ou segmento, no qual certo consenso relacional foi conquistado, para que a diferença inerente à vida se iguale ou se torne similar. 
Por outro lado, as linhas flexíveis são responsáveis pelos afetamentos que ocorrem nas relações, criando condições para o estabelecimento de zonas de indeterminação e de agenciamentos. Nas linhas flexíveis, os estratos se encontram mais diluídos, constituindo-se em uma conjugação de fluxos diversos e heterogêneos que outrora se encontravam homogeneizados consensualmente nos segmentos, nos setores que integram as políticas públicas. Desse modo, linhas de outro teor são traçadas nas linhas duras, no plano de organização, realizando fissuras nesses segmentos e contribuindo para a formação de linhas de fuga. Estas criam zonas de indeterminação entre os setores e entre as subjetividades, compõem processos de subjetivação que produzem agenciamentos, permitindo o aflorar o coletivo e convergindo em processos que arrastam o rizoma para o novo. Conjugam movimentos de desestratificação, afirmam a diferença sustentando processos inventivos e compõem o plano de consistência. Movimento necessário, no nosso entender, para que a intersetorialidade se exerça e deslocamentos subjetivos se façam.

Cabe salientar que esses dois planos - o plano de organização e o plano de consistência-encontram-se justapostos de forma imanente. Formados pela mesma matéria, os fluxos, mas com funcionamentos diferentes: dissociativo e homogeneizante no plano de organização, e conectivo e fluido no plano de consistência. $\mathrm{O}$ agenciamento que, nessa perspectiva teórica, sustenta os deslocamentos subjetivos e também a intersetorialidade, ocorre entre esses dois planos e entre esses dois regimes de funcionamento, que coexistem sem determinação e hierarquia. $\mathrm{O}$ agenciamento se efetiva toda vez que há um acoplamento de um conjunto de relações, alinhavando elementos das mais variadas ordens: materiais, subjetivas, coletivas e processuais, reunindo dimensões heterogêneas e nos lançando na fluidez rizomática. Portanto, o agenciamento retira os profissionais dos diferentes equipamentos da interioridade e das políticas setoriais da fixidez das linhas duras e os arremessa no coletivo e na processualidade, associando os planos de organização e de consistência, os quais são processos de subjetivação que pretendemos rastrear nesse texto, associados à prática da intersetorialidade na saúde mental.

Nesse rastreamento, vale lembrar, a intersetorialidade caminha junto com a noção de território, que não se refere somente ao espaço geográfico. O território representa muito mais do que o município ou a região na qual se instalam os equipamentos das políticas públicas, consiste também nas conexões estabelecidas entre as subjetividades, espaços relacionais de vida, de permutas, de sustentação e ruptura de vínculos cotidianos que constroem sentidos e significados para os que nele vivem e circulam (Romagnoli, 2014). Assim, o território se mostra como algo vivo, dinâmico - muito diferente de como é visto pelas equipes que não trabalham diretamente nele - e com abordagens diversas pelos diferentes setores das políticas públicas que o abrange.

As pesquisas que realizamos tiveram objetivos distintos, mas guardam em comum o trabalho de pesquisa-intervenção em cenários de importante vulnerabilidade social e com foco na produção de saúde mental com usuários das redes intersetoriais locais. $\mathrm{O}$ trabalho da pesquisa-intervenção consiste em procurar caminhar junto à realidade que é mutante, buscando o ineditismo da experiência humana que esteja a produzir a diferença, operando desse modo no plano dos acontecimentos. Trata-se de fazer "pesquisa em situação", o que significa dizer que o pesquisador rompe radicalmente com a falácia da neutralidade e assume que faz, ele próprio, parte do campo que pretende investigar. Para isso, adota o pressuposto que conhecer e intervir fazem parte de um continuum que se mescla no nível das implicações e afetações entre sujeito e objeto do conhecimento. Assim, conhecer é acompanhar processos e movimentos que se fazem entre equipes, serviços e territórios.

Os territórios onde se desenvolveram as pesquisas são muito diversos, assim como as características culturais locais, o que conduz a necessária consideração das singularidades que nos impedem de desenvolver reflexões com uma pretensão de generalização. Guardamos em comum a perspectiva teórico-metodológica da esquizoanálise que está interessada em cartografar as singularidades dos contextos de pesquisa, em acompanhar as linhas duras e as fissuras desses territórios, bem como as capturas e resistências que se observam nos encontros entre pessoas e instituições com os quais nos encontramos no campo.

Desse modo, as duas pesquisas são compostas de dois eixos concomitantes de ação para a produção de seus dados, compreendendo a formulação de um campo de análise e um campo de intervenção, que se interpenetram a todo momento. O campo de análise se constitui de levantamento e discussões permanentes da literatura sobre as ideias de Gilles Deleuze, Félix Guattari e Michel Foucault, que sustentam a proposta de pesquisa-intervenção desse estudo, e autores nacionais que trabalham nessa vertente. Efetuamos, ainda, o estudo da intersetorialidade, focando na inclusão social e discutindo a violação de direitos e a vulnerabilidade social nos contextos estudados. O campo de intervenção é formado através de um projeto de trabalho coletivo com a equipe dos profissionais que integram o NIR-T em Belo Horizonte e com a equipe que trabalha com a população de rua em Natal, acolhendo as demandas e dificuldades locais. Esse trabalho envolve também a participação das próprias pessoas em situação de rua, que assumem a liderança do Movimento da População de Rua local e de outras pessoas que encontramos nessa condição, com as quais temos contato frequente através de projetos de pesquisa, extensão universitária e estágios curriculares de graduação. Para a produção dos dados utilizamos contatos informais, grupos de discussão, entrevistas, questionários, rodas de conversa, eventos, diários de campo pesquisa e restituições do material para análise conjunta com as equipes e coletivos envolvidos.

Vale ressaltar que ambas as pesquisas respeitaram os preceitos éticos da pesquisa com seres humanos e foram realizadas com o livre consentimento dos sujeitos, que assinaram o TCLE (Termo de Consentimento Livre e Esclarecido) em todas as entrevistas realizadas. 


\section{Conhecendo os Territórios e suas Tensões}

Natal, capital do estado do Rio Grande do Norte, no Nordeste brasileiro, tem uma população de quase um milhão de habitantes, cuja prefeitura possui alguns programas intersetoriais recentes (notadamente na área do cuidado a usuários de álcool e de outras drogas), mas não possui nenhuma unidade ou órgão administrativo responsável por promover a intersetorialidade entre as políticas públicas. Nela, realizamos uma pesquisa-intervenção junto à população em situação de rua que teve por objetivo conhecer as condições de vida e principais violações de direitos humanos sofridas por essa população. Para tanto, realizamos, ao longo de dois anos, entrevistas semiestruturadas com 157 pessoas em situação de rua, ao lado de oficinas de informática e de formação política, rodas de conversa e eventos em diferentes pontos do centro da cidade. Dessa pesquisa, apresentamos aqui um recorte relativo ao acesso às políticas públicas e à intersetorialidade como fundamento para a atenção a essa população.

O Brasil possui a Política Nacional da População em Situação de Rua, conquistada por força da atuação do Movimento Nacional da População em Situação de Rua (MNPSR), e que foi instituída no ano de 2009, a partir do Decreto Presidencial $\mathrm{n}^{0}$ 7.053/09. Observamos, no entanto, que as políticas públicas no município de Natal não atendem de modo qualificado e suficiente esse segmento populacional, como preconizado pela legislação, além de não possuírem nenhuma política pública específica para essa população, sendo destinados para ela apenas dois serviços da assistência social (um albergue para abrigamento noturno com apenas 58 leitos e um Centro de Referência da Assistência Social para População de Rua - Centro Pop) e três equipes de Consultório na Rua (CnaR) vinculadas à Atenção Primária em Saúde e que atendem às demandas de saúde das pessoas em situação de rua das regiões leste e sul da cidade, às vezes fazendo atendimentos na própria rua ou encaminhando as pessoas para os serviços.

A partir do encontro com essa população e seus depoimentos, mapeamos uma série de problemas e vulnerabilidades nas suas condições de vida e saúde, que são agravados pela falta de acesso às políticas públicas em geral, baixa qualificação das equipes profissionais existentes para a atenção a esse público e fragilidades ou inexistência de vínculos dessas pessoas com os dispositivos e serviços básicos de moradia, educação, trabalho, justiça, segurança pública, saúde e assistência social. Assim, destaca-se, por exemplo, o fato de que elas acessam o SUS e o SUAS, tendo como porta de entrada prioritária os serviços de maior complexidade e em situações de agravamento da sua condição de saúde e de vulnerabilidade social (notadamente a rede hospitalar e os serviços de urgência e emergência), sem que o trabalho de prevenção e promoção de saúde e de proteção social atinjam essas pessoas.

Sabemos que a população em situação de rua desafia os princípios de universalidade, equidade e integralidade do SUS e encontra-se à margem das redes de atenção à saúde e de proteção social, sendo alvo de políticas assistencialistas, compensatórias e focalizadoras. Esse desafio se dá pela necessidade de se sustentar a diferença frente ao funcionamento classificatório e homogeneizante ainda presente nas práticas em saúde mental. Um dos motivos para tal panorama está na cultura de preconceito e exclusão de que essas pessoas são alvo. Entre as barreiras evidenciadas de acesso estão: a burocratização do serviço e o preconceito dos profissionais motivados pela aparência dos usuários (falta de roupas e higiene adequada), a ausência de documentos de identificação e endereço fixo, e/ou pela frequente condição de uso abusivo ou excessivo de álcool e outras drogas, às vezes com quadros de intoxicação, como acontece em outras capitais do nordeste brasileiro (Ferreira, Rozendo \& Melo, 2016).

À semelhança dos achados de Ferreira et al. (2016), destacamos as equipes de Consultório na Rua como importantes para o acesso à saúde pela atenção primária, bem como o protagonismo das mesmas no tensionamento das demais políticas para a atenção à população em situação de rua de modo integral e digno. Ficou evidente como as pessoas nessa situação possuem vínculo importante com os profissionais das equipes de CnaR, os quais terminam por assumir sozinhos uma série de demandas que são de natureza intersetorial e que estão além da sua capacidade resolutiva. Tal situação produz frequentemente o adoecimento dos profissionais, sobrecarga de trabalho e sentimento de impotência, pois é fato que os problemas enfrentados por essa população reúnem demandas de ordem social, econômica, sanitária e assistencial amplas e graves.

A comunicação entre as equipes dos serviços de saúde e assistencial acontece apenas de modo pontual, normalmente em situações emergenciais e no sentido do encaminhamento sem responsabilização pela continuidade dos cuidados, sem comunicação entre os serviços e setores para a resolução dos problemas enfrentados pelos usuários. Presenciamos aqui as linhas duras dos setores e das questões pessoais enlaçando a prática intersetorial. Esse cenário fica evidente em relato registrado em diário de campo:

A entrevistada me disse que enfrenta alguns problemas de saúde. Segundo ela, tem tuberculose, asma e depressão. E algo que agrava sua situação é o uso de drogas: usa maconha, crack, cocaína, cigarro, e ainda consome bebidas alcoólicas. Lamentou muito durante a entrevista ter andado o dia inteiro em busca de atendimento na rede de saúde e não ter conseguido [atendimento]. Falou que se esforça para seguir à risca o tratamento contra a tuberculose, mas não tem tido o apoio dos 
próprios serviços de saúde. Disse que foi ao posto de saúde do bairro, mas estavam em greve e mandaram-na para o hospital X. De lá, encaminharam-na para o hospital Y (referência em doenças infecto contagiosas). Em momento algum tais profissionais se preocupam comcomo ela ia chegar nesses lugares doente e sem dinheiro (Diário de campo do dia 30 de maio de 2014).

Vale destacar ainda que ela não conseguiu chegar ao hospital indicado por falta de dinheiro para o transporte e, ao procurar ajuda em serviço de referência do SUAS, não foi atendida sob a justificativa de que estava alcoolizada. Observamos, assim, um quadro de violação de direitos por negligência das instâncias públicas e uma clara desarticulação entre os setores da assistência social e saúde.

Além disso, as situações em que os usuários apresentam problemas de saúde mental conduzem invariavelmente, no caso dos dispositivos da assistência social e de alguns serviços de saúde, à práticas disciplinares que condicionam o uso dos serviços à abstinência e ao obrigatório tratamento no CAPS Ad (Centro de Atenção psicossocial para álcool e outras drogas), o que é compreendido pelos profissionais como uma prática intersetorial. Vemos, assim, que os espaços institucionais destinados à população em situação de rua muitas vezes constituem-se como lugares pobres de significado para as pessoas e que não conseguem produzir efetivas transformações em suas vidas. Podem ser compreendidos ainda como "não lugares" (Augé, 1993), dada a ausência de história, de identidade, de relação afetiva, e nos quais predomina a precariedade, a disciplina e o controle.

$\mathrm{Na}$ ausência de ações intersetoriais efetivas e que preservem os direitos dos usuários, observamos a construção de itinerários próprios de cuidado por parte das pessoas em situação de rua. Tais itinerários desviam-se dos fluxos regulares das redes assistenciais, dadas as dificuldades de vinculação com essa clientela e das redes em absorver suas demandas de modo articulado, como no caso acima relatado. Assim, é comum que os usuários busquem pontos alternativos de apoio social em entidades e pessoas ligadas a organizações não governamentais, comunidades e coletivos religiosos e movimentos sociais, trilhando suas próprias linhas nômades e flexíveis, que podem vir a se transformar em outras formas de lidar com a vulnerabilidade. Nos casos que envolvem problemas associados ao uso de álcool e outras drogas, a precária vinculação de pessoas em situação de rua com os CAPS Ad, as conduzem à busca na rede de atenção básica por medicamentos ansiolíticos para suportar a abstinência ou para incrementar o efeito de certas drogas. Assim, mantém-se com a atenção básica uma relação superficial apenas para renovação das receitas médicas sem qualquer continuidade de cuidados, o que vem sendo problematizado pela ação dos profissionais dos CnaR.

Nesse contexto, as comunidades religiosas que se propõe a “cura das drogas" são vistas como alternativas. Operando através da abstinência sustentada pelos ritos religiosos, sem tratamento médico específico e impondo a disciplinarização das condutas no cotidiano institucional, as práticas dessas comunidades terapêuticas produzem efeitos de evasão dos usuários e crises de abstinência não tratadas. O que se observa, então, é que as redes de sustentação menos frágeis são aquelas construídas solidariamente na rua, com outras pessoas na mesma situação, que às vezes se configuram como linhas de fuga, ou com entidades que realizam trabalhos na cidade, como é o caso do próprio movimento social (MNPR) e de entidades de defesa de Direitos Humanos, os quais promovem espaços coletivos de formação política e acompanhamento dos casos, tensionando as políticas públicas para a garantia de direitos dessa população e produzindo alguma flexibilização nas relações e outras possibilidades de enfrentamento.

Podemos dizer que diante das linhas duras, em sua segmentaridade burocrática e excludente, que compõem as redes formais das políticas públicas locais, as pessoas em situação de rua constroem alternativas de cuidado heterogêneas, desviantes e coletivas, ainda que nem sempre resolutivas em longo prazo. Buscam na fluidez do cotidiano e dos encontros solidários as possibilidades de sustentação da vida.

Belo Horizonte, capital do estado de Minas Gerais, na região Sudeste, possui quase 3 milhões de habitantes, cuja prefeitura instituiu os Núcleos Intersetoriais Regionais (NIR's), vinculados às Secretarias de Administração Regional Municipal e localizados em cada uma das nove regionais do município com o intuito de promover a intersetorialidade e a descentralização das ações de inclusão social (Decreto no 13.660 de 03 de agosto de 2009). Dentre os NIR's está o NIR Técnico, que atua em um espaço intersetorial para discussão dos casos graves de violação de direitos afins às políticas setoriais regionais de modo a agilizar e qualificar a entrega de serviços públicos à população demandante. Composto por profissionais indicados, esse espaço visa ainda a fortalecer a interlocução entre as gerências das políticas setoriais regional, compreendendo e delimitando o papel de cada um no tratamento dos casos apresentados.

Neste texto, apresentamos os resultados parciais da pesquisa-intervenção "Intersetorialidade, famílias e processos de subjetivação", financiada pelo Conselho Nacional de Pesquisa (CNPQ), focando na área da saúde mental. Este estudo tem como objetivo analisar a intersetorialidade a partir das relações estabelecidas no NIR Técnico de uma das regionais da Prefeitura Municipal de Belo Horizonte, enfatizando o modo de gestão do trabalho social entre as políticas setoriais, as equipes e as famílias com o intuito favorecer a invenção de novas formas de expressão nesses grupos. Esse objetivo foi criado coletivamente com a equipe pesquisada, a partir dos impasses que encontram em seu cotidiano e que dificultam a sustentação efetiva das suas ações. Os principais impasses apontados pela equipe foram: dificuldade com a inserção da ação intersetorial nos planejamentos institucionais; atravessamento de uma mentalidade ainda setorizada e personificada 
que circula nos equipamentos; desconhecimento dos técnicos da ação setorial, que, muitas vezes, ao contrário do que esta propõe, vêem como uma sobrecarga de trabalho; ineficiência nos encaminhamentos e acolhimentos, dentre outros. Por outro lado, a equipe percebe que as famílias geralmente sentem que estão sendo invadidas pelas ações intersetoriais, uma vez que são muitos técnicos e serviços trabalhando com esses grupos. Esses foram os problemas iniciais e apresentamos aqui o recorte das questões que afloraram na pesquisa já em curso acerca do cotidiano da intersetorialidade na saúde mental.

Embora o NIR convoque uma discussão intersetorial dos "casos problema", como as equipes designam, dos casos em que os serviços vêm encontrando graves vulnerabilidades das mais variadas ordens e muitas vezes sem conseguir dar um encaminhamento, essa discussão em si não garante a construção de saídas inventivas para os usuários. Nesses encontros, o encaminhamento dado ao caso geralmente se dá pelo serviço no qual o usuário ou a família tenha maior afinidade ou se sinta menos ameaçado, para, em seguida, associar os outros serviços envolvidos. Com frequência, o serviço no qual isso ocorre é o posto de saúde, equipamento da atenção básica, apesar da saúde mental ser demandada em boa parte dos casos discutidos. Observamos em nosso estudo, no entanto, uma articulação precária entre o CAPS e a rede de atenção básica, com pouco diálogo e dificuldades de comunicação, como ocorre em Natal, mesmo havendo um espaço o institucional para que essa troca se viabilize. Novamente, a presença das linhas duras do que está arraigado em cada setor.

A demanda da saúde mental na atenção básica, nos equipamentos da política de assistência social e da educação são altas, e muitos profissionais não se sentem em condições de lidar com os usuários portadores de transtorno mental. Nesse sentido, com frequência solicitam à atenção secundária e ao NASF, que se sentem sobrecarregados com os casos encaminhados pelo NIR. Dimenstein e Liberato (2009) discutem que a falta da rede de equipamentos sociais promove a reprodução da lógica setorial, de relações homogeneizantes, a burocratização das práticas dos profissionais e a sobrecarga dos profissionais da saúde. Atestam ainda que a articulação precária entre o CAPS e a rede de atenção básica está vinculada, entre outros fatores, à resistência da equipe do CAPS, por compreender como aumento do serviço, que já é excessivo e não como uma possiblidade de troca e trabalho conjunto.

Nessa direção, a intersetorialidade é vivenciada como um incômodo, em um cotidiano já pleno de tarefas. Essa mesma realidade é denunciada por Cavalcanti e Lucena (2016), que apontam que é comum esses profissionais já contarem com uma sobrecarga de obrigações dentro de seus próprios setores, o que contribuiu para a manutenção do conservadorismo das ações desenvolvidas. Nesse sentido, o rizoma se endurece, formata as práticas sustentando-se no cansaço. Os casos que vão para o NIR, quase sempre, se não há confirmação diagnóstica, possuem suspeitas de ter relação com saúde mental (transtornos mentais) por parte dos profissionais envolvidos, seja da pessoa referência da família, seja de outros membros da família. Essa questão desvela ainda “ (...) a necessidade de um técnico mais próximo da rede de saúde mental estar acompanhando para ajudar a delimitar as condutas e encaminhamentos”, como coloca uma técnica do NIR. O que nem sempre acontece, até mesmo por causa dessa sobrecarga.

Por outro lado, essa sobrecarga também aparece na questão "tudo é saúde mental", gerando uma psicologização dos casos que são em si complexos, com atravessamentos das mais variadas ordens: sociais, econômicos, cultuais, dentre outros. Entendemos que essa demanda insiste em que os casos sejam tratados de forma individual, estabelecendo uma composição esvaziada politicamente e tornam invisíveis as formas de dominação e exploração que perpassam as questões dos usuários em forte vulnerabilidade social. Corre-se o risco de que conflitos e assujeitamentos sejam entendidos como patologia, atuando para a despolitização das relações sociais, privatizando os problemas sociais e políticos. Quando isso ocorre, os casos são particularizados em demasia, como se o grupo familiar fosse o único causador dos problemas apresentados.

Outro ponto que emerge nos contatos com os profissionais e no acompanhamento das reuniões do NIR Técnico é a falta da rede que tenha integração e articulação dos serviços, o que contribui para que os modelos de cada setor vigorem e impeçam a ações conjuntas e a aproximação entre cidadania e subjetividade. Essa ausência aumenta os riscos da psicologização da questão social no acompanhamento das famílias e dos usuários ao enfatizar o que deveriam mudar em sua dinâmica interna, em detrimento de leituras distintas acerca da multideterminação da sua problemática, contribuindo para a ideia de que "tudo é saúde mental", discutida acima, e impedindo que a transversalidade se faça para tentar evitar o risco dos serviços, na prática, continuarem centralizados e distantes das necessidades reais da população brasileira, operando por rupturas e não por agenciamentos, que viabilizam uma rede rizomática, e conectando os mais variados elementos da realidade e dos setores, não se reportando a uma única combinação.

\section{Considerações Finais: O que Podemos Pensar das Experiências e de seus Desafios?}

Pensar a intersetorialidade como princípio operativo das políticas públicas exige que o objeto prioritário das ações sejam pessoas que historicamente vivem em invisibilidade, excluídas da vida social das cidades, como nos diz Venturini (2009, pp.205-6): 
Certamente existiam cem, mil cidades invisíveis desconhecidas para nós. Entre as pessoas que sofrem de uma doença mental formalmente reconhecida e aquelas que sofrem de "outras" condições de vulnerabilidade psicossocial, geradas pela pobreza, pela violência, pela insegurança e pelo abandono, pela emigração forçada, pela exclusão, havia de existir muitas coisas em comum: estigma, discriminação, violação de direitos. (pp. 205-6)

Assim, nos propusemos a “olhar” através das pesquisas algumas dessas “cidades invisíveis” (Calvino, 1990) que se revelam no cotidiano das vidas das pessoas em vulnerabilidade psicossocial e a mapear elementos importantes na construção das políticas intersetoriais necessárias. $\mathrm{Na}$ análise dos achados, parece-nos pertinente considerar os princípios rizomáticos do pensamento (Deleuze \& Guattari, 1980) no plano de imanência da vida que se faz nas cidades, no interior das redes assistenciais e sanitárias, e entre as redes nas ações intersetoriais. Dentre tais princípios, destacamos a conexão, a heterogeneidade, a multiplidade e a cartografia na composição das políticas e ações intersetoriais.

A produção de linhas duras na relação da intersetorialidade na saúde mental, na rede rizomática dessa prática, aparece quando se produz na heterogeneidade relações de poder que sustentam uma primazia, uma hierarquia ou um reducionismo. São composições dessas estratificações, por exemplo: a falta de capacitação para lidar com a doença mental e com a pobreza extrema; a sensação de sobrecarga de trabalho; a psicologização dos casos; a falta de um trabalho articulado efetivamente e o fato de que, quando existe, carece de avaliações das ações em conjunto após os encaminhamentos; a falta de responsabilização pela continuidade dos cuidados e de implicação com os projetos de vida das pessoas atendidas.

Todos esses pontos formam nós cristalizados, arborescências que inviabilizam a construção coletiva, uma vez que os sistemas arborescentes são hierárquicos e comportam centros de significâncias que reduzem a realidade a certas interpretações e impedem que os fluxos de produção de vida sejam promovidos. Revelam também como as conexões são frágeis e facilmente capturadas pelos instituídos disciplinares e burocráticos do trabalho assistencial, pouco sensível para as multiplicidades próprias e necessárias às composições rizomáticas, flexíveis, horizontalizantes e desinstitucionalizantes.

Esses obstáculos nos fazem pensar que não devemos ter "árvores na cabeça", uma vez que a natureza em si não é arborescente, não tem origem nem fim, não se deixa fixar em uma representação, não possui um modelo a reproduzir. Vale lembrar que as linhas que constituem o rizoma não se deixam capturar completamente nos estratos, exatamente pela imanência, e neles aparecem fissuras, brechas, rupturas que deixam escapar fluxos de variação contínua, forças nômades que buscam conexões. Sendo ruptura, o rizoma nesse modo de funcionamento, não efetua dualismos, não produz segmentos e territórios fixos, mas se entrega a processualidade, produz agenciamentos como nos lembra Jacques (2014).

Assim, o desafio da intersetorialidade está na produção de novas sensibilidades e formas de subjetivação nos espaços coletivos e institucionais que promovam agenciamentos capazes de lidar com as imprevisibilidades, as instabilidades e as complexidades que o encontro com as precariedades da vida e com a loucura (excessos e desvios) produz, sem perder de vista os movimentos instituintes que promovem no cotidiano das relações intra e interinstitucionais.

Para tanto, parece necessária a capacidade de estranhar as estabilidades e se indignar com as violações de direitos e sofrimentos vividos de modo que seja possível promover outras direções e desestabilizar as certezas no sentido da "construção de novos modos de operar políticas públicas que se pretendem garantidoras de Direitos Humanos na conjuntura de um estado neoliberal, em um mundo globalizado" (Arraes-Amorim \& Nobre, 2015, p. 109). A evocação da garantia desses direitos fundamentais através da execução de políticas públicas é um grande desafio num país como o Brasil, no qual as maiores e mais graves infrações aos direitos humanos são cometidas pelo Estado. Tal quadro tem se agravado nos últimos anos com o recrudescimento do neoliberalismo, que tem como corolário, no caso brasileiro, o avanço do conservadorismo e o enxugamento na efetivação de direitos sociais, ao lado do crescimento do Estado punitivo em larga escala, que tem como alvo prioritário pessoas negras e pobres, principais usuários das redes de saúde e assistência. A nossa aposta com relação à intersetorialidade não desconsidera essas contradições e desafios. Ao contrário, entendemos que, nas brechas e fendas produzidas por esses impasses, é possível articular estratégias que coloquem em movimento outras possibilidades, ainda que circunstanciais e momentâneas, a serem conquistadas e reconquistadas, inventadas e reinventadas, a cada nova experiência.

$\mathrm{Na}$ direção da invenção, a intersetorialidade consiste em reunir os fragmentos dos setores envolvidos nos casos discutidos para multiplicar os afetos e sustentar indagações que produzam outros trajetos, novos percursos, como destaca Lee (2014) ao estudar o rizoma na escrita. Nesse agenciamento de mundos, vetores de forças produzem diferenças. Dias, Parente, Vasconcelos e Dias (2014) pontuam como intercessores dessa ruptura o compromisso dos profissionais com as políticas públicas, o conhecimento das atribuições do próprio setor e dos outros setores do equipamento, e o conhecimento do território em que se atua. Esses são pontos visíveis, ainda estratificados, mas que podem produzir agenciamentos, pondo em jogo a potência, conectando os profissionais de diferentes setores com suas intervenções distintas e com os usuários vulneráveis. Pontos que se enredam em linhas de fuga e que podem trazer o coletivo, produzir enunciações e fazer com que a intersetorialidade se efetive.

Nesse sentido, destacamos a ação da maioria dos profissionais que se dispõem a trabalhar nos Consultórios na Rua, que, apesar da burocratização instituída das suas ações, têm procurado, em determinadas circunstâncias, promover linhas flexíveis 
que possam vir a tornarem-se linhas de fuga nas ações de redução de danos e articulações com os movimentos sociais e entidades apoiadoras da população de rua. Destacamos também a ação de coletivos organizados que trabalham junto a usuários da rede de saúde mental e da população em situação de rua no fomento à organização política e na articulação entre práticas que se revelam como uma via de produção de outros modos de subjetivação e vida das pessoas em situação de vulnerabilidade social, importantes frente às graves violações de direitos que sofrem no cotidiano. É, como diz Vasconcelos (2008), o poder que brota da dor e da opressão e que se exercita no interior dos Movimentos de Luta Antimanicomial e, mais recentemente, no Movimento Nacional da População de Rua (MNPR). Na micropolítica do cotidiano, vislumbra-se a potência dos encontros entre sujeitos com suas singularidades que, num plano comum de problemas e opressões, produzem agenciamentos instituintes que convocam os aparatos públicos a se reinventarem a partir das demandas que se apresentam para a população.

Ressaltamos ainda a abertura do Núcleo Intersetorial Regional (NIR) para dialogar na diferença, ter ações conjuntas, buscar saídas coletivas, mas é preciso ter cautela. O poder em rede admite agenciamentos, conexões, que podem derivar tanto em uma reprodução quanto em uma invenção. Tanto é assim que um dos grandes desafios encontrados se refere ainda ao acompanhamento do encaminhamento do caso, fato que incomoda a maioria dos técnicos e gestores que discutem saídas no NIR. Em suas práticas intersetoriais, não aconteceram avaliações das ações em conjunto após as intervenções. Com isso, fica-se sem saber se ação intersetorial teve, ou não, uma eficácia junto aos usuários. Correndo-se o risco de que, mesmo depois dos encontros e das discussões em conjunto, a intersetorialidade, de fato, não se exerça. Por outro lado, na direção da invenção, a intersetorialidade consiste em reunir os fragmentos dos setores envolvidos no caso discutido para multiplicar os afetos e sustentar indagações que produzam outros trajetos, novos percursos que possam ser, de fato, trilhados.

Ressaltamos, por fim, em ambas as experiências discutidas, a criação de novas relações entre os setores, entre os próprios técnicos da saúde mental, dos técnicos com os serviços, e dos usuários com os equipamentos e com os técnicos, que se faz pela conexão de diferenças em um plano de imanência, tentando-se lidar com a complexidade presente no campo social. Esse movimento da transversalidade que nos convoca a fazer rizoma como experimentação.

\section{Referências}

Akerman, M., Sá, R. C., Moysés, S., Rezende, R., \& Rocha, D. (2014). Intersetorialidade? Intersetorialidades! Ciência, Saúde Coletiva 19(11), 4291-4300. DOI: 10.1590/1413-812320141911.10692014

Andrade, L. O. M. (2006). A saúde e o dilema da intersetorialidade. São Paulo: Hucitec.

Augé, M. (1993). Não lugares introdução a uma antropologia da supermodernidade. Campinas: Papirus.

Arraes-Amorim, A. K., \& Dimenstein, M. (2009). Desinstitucionalização em saúde mental e práticas de cuidado no contexto do serviço residencial terapêutico. Ciência e Saúde Coletiva, 14(1), 195-204.

Arraes-Amorim, A. K., \& Nobre, M. T. (2015). Saúde mental, luta antimanicomial e direitos humanos no contexto potiguar: Por outras sensibilidades. In I. L. Paiva, C. Souza, D. A. Valença, \& A. Araújo (Orgs), Direitos humanos e práxis: Experiências do CRDH-RN (pp. 107-128). Natal: EDUFRN.

Barros, R. B., \& Passos, E. (2004). Clínica: As modulações do capitalismo. Lugar Comum, 19-20(Esp.), 159-171.

Bronzo, C. (2010). Intersetorialidade, autonomia e território em programas municipais de enfrentamento da pobreza: Experiências de Belo Horizonte e São Paulo. Planejamemónto e Políticas Públicas, 2(35),120-159.

Calvino, I. (1990). As cidades invisíveis. São Paulo: Companhia das Letras.

Cavalcanti, P. B., \& Lucena, C. M. F. (2016). O uso da promoção da saúde e a intersetorialidade: Tentativas históricas de integrar as políticas de saúde e educação. Polêmica, 16(1), 24-41. DOI: 10.12957/polemica.2016.21332

Ckagnazaroff, I. B., \& Mota, N. R. (2003). Considerações sobre a relação entre descentralização e intersetorialidade como estratégias de modernização de prefeituras municipais. Economia e gestão, 3(6), 23-41.

Constituição da República Federativa do Brasil. (1988). Brasília: Senado. 
Deleuze, G., \& Guattari, F. (1980). Mille Plateaux: Capitalisme et schizophrénie. Paris: Editons de Minuit.

Deleuze, G., \& Parnet, C. (1995). Dialogues. Paris: Flammarion.

Delgado, P. G. (2013). Supervisão clínico-institucional: Conceito e história. In A. Nunes Filho (Org.). Supervisão em Saúde Mental (pp. 18-27). Belo Horizonte: ESP-MG.

Dias, M. S. A., Parente, J. R. F., Vasconcelos, M. I. O., \& Dias, F. A. C. (2014). Intersetorialidade e Estratégia Saúde da Família: tudo ou quase nada a ver? Ciência \& Saúde Coletiva, 19(11), 4371-4382. DOI: 10.1590/1413-812320141911.11442014

Dimenstein, M., \& Liberato, M. T. (2009). Desinstitucionalizar é ultrapassar fronteiras sanitárias: O desafio da intersetorialidade e do trabalho em rede. Cadernos Brasileiros de Saúde Mental, 1(1), 1-10.

Dispõe sobre a proteção e os direitos das pessoas portadoras de transtorno mental e redireciona o modelo assistencial em saúde mental. Lei 10.216, de 06 de abril de 2001. (2001). Link

Ferreira, C. P. da S., Rozendo, C. A., \& Melo, G. B. de. (2016). Consultório na Rua em uma capital do Nordeste brasileiro: O olhar de pessoas em situação de vulnerabilidade social. Cadernos de Saúde Pública, 32(8), 2595-2606.

Góes, F. T., \& Machado, L. R. de S. (2013). Políticas educativas, intersetorialidade e desenvolvimento local. Educação e Realidade, 38(2), 627-648.

Guattari, F. (1987). Revolução molecular: Pulsações políticas do desejo. São Paulo: Brasiliense.

Inojosa, R. M. (2001). Sinergia em políticas e serviços públicos: Desenvolvimento social com intersetorialidade. Cadernos FUNDAP, 22, 102-110.

Institui a Política Nacional para a População em Situação de Rua e seu Comitê Intersetorial de Acompanhamento e Monitoramento, e dá outras providências. (2009). Decreto $\mathrm{n}^{\circ}$ 7.053, de 23 de dezembro de 2009. Presidência da República. Diário Oficial da União, Poder Executivo, Brasilia.

Institui os Núcleos Intersetoriais Regionais - NIR, e dá outras providências. (2009). Decreto no 13.660 de 03 de agosto de 2009. Diário Oficial do Município, Belo Horizonte.

Jacques, V. (2014). Deleuze pas à pas. Paris: Editions Elipses.

Lancetti, A., \& Amarante, P. (2008). Saúde mental e saúde coletiva. In G. W. Campos (Org.). Tratado de saúde coletiva (pp. 615-634). Rio de Janeiro: Fiocruz.

Lee, C-W. (2014). Le concept de plateau chez Deleuze et Guattari: Ses implications epistemologique et ethique. Kriterion: Revista de Filosofia, 55(129), 79-97. DOI: 10.1590/S0100-512X2014000100005

Monnerat, G. L., \& Souza, R. G. (2011). Da seguridade social à intersetorialidade: Reflexões sobre a integração das políticas sociais no Brasil. Revista Katálysis, 14(1), 41-49. DOI: 10.1590/S1414-49802011000100005

Romagnoli, R. C. (2014). Acerca da noção de território no SUAS: A proposta esquizoanalítica. In R. C. Romagnoli \& M. I. C. Moreira (Orgs.), O Sistema Único de Assistência Social - SUAS: A articulação entre psicologia e o serviço social no campo da proteção social, seus desafios e perspectivas (pp. 117-131). Curitiba: Editora CRV.

Sposati, A. (2013). Proteção social e seguridade social no Brasil: Pautas para o trabalho do assistente social. Serviço Social e Sociedade, (116), 652-674. DOI: 10.1590/S0101-66282013000400005

Vasconcelos, E. M. (2008). Abordagens psicossociais II: Reforma Psiquiátrica e saúde mental na ótica da cultura e das lutas populares. São Paulo: Editora Hucitec. 
Venturini, E. (2009). A cidade dos outros. Fractal: Revista de Psicologia, 21(2), 203-222.

\section{Endereço para correspondência}

Roberta Carvalho Romagnoli

Email: robertaroma1@gmail.com

Ana Karenina de Melo Arraes Amorim

Email: akarraes@gmail.com

Ana Kalliny de Sousa Severo

Email: akssevero@gmail.com

Maria Teresa Nobre

Email: teresa-nobre@uol.com.br 